Marquette University

e-Publications@Marquette

Exercise Science Faculty Research and Publications

Exercise Science, Department of

4-1-2014

\title{
The Stroke-related Effects of Hip Flexion Fatigue on Over Ground Walking
}

Megan M. Rybar

Marquette University

Eric R. Walker

Marquette University

Henry Kuhnen

Marquette University, henry.kuhnen@marquette.edu

Daniel R. Ouellette

Marquette University

Reivian Berrios

Marquette University

See next page for additional authors

Accepted version. Gait \& Posture, Vol. 39, No. 4 (April 2014): 1103-1108. DOI. (C) 2014 Elsevier. Used with permission. 
Authors

Megan M. Rybar, Eric R. Walker, Henry Kuhnen, Daniel R. Ouellette, Reivian Berrios, Sandra K. Hunter, and Allison Hyngstrom 


\title{
The Stroke-Related Effects of Hip Flexion Fatigue on Over Ground Walking
}

\author{
Megan M. Rybar \\ Department of Physical Therapy, Marquette University \\ Milwaukee, WI \\ Eric R. Walker \\ Department of Biomedical Engineering, Marquette University \\ Milwaukee, WI \\ Henry R. Kuhnen \\ Department of Biomedical Engineering, Marquette University \\ Milwaukee, WI \\ Daniel R. Ouellette \\ Department of Physical Therapy, Marquette University \\ Milwaukee, WI \\ Sandra K. Hunter \\ Department of Physical Therapy, Marquette University \\ Milwaukee, WI \\ Allison S. Hyngstrom \\ Department of Physical Therapy, Marquette University \\ Milwaukee, WI
}


NOT THE PUBLISHED VERSION; this is the author's final, peer-reviewed manuscript. The published version may be accessed by following the link in the citation at the bottom of the page.

\begin{abstract}
Individuals post stroke often rely more on hip flexors for limb advancement during walking due to distal weakness but the effects of muscle fatigue in this group is not known. The purpose of this study was to quantify how stroke affects the influence of hip flexor fatigue on over ground walking kinematics and performance and muscle activation. Ten individuals with chronic stroke and 10 without stroke (controls) participated in the study. Maximal walking speed, walking distance, muscle electromyograms (EMG), and lower extremity joint kinematics were compared before and after dynamic, submaximal fatiguing contractions of the hip flexors ( $30 \%$ maximal load) performed until failure of the task. Task duration and decline in hip flexion maximal voluntary contraction (MVC) and power were used to assess fatigue. The stroke and control groups had similar task durations and percent reductions in MVC force following fatiguing contractions. Compared with controls, individuals with stroke had larger percent reductions in maximal walking speed, greater decrements in hip range of motion and peak velocity during swing, greater decrements in ankle velocity and lack of modulation of hip flexor EMG following fatiguing dynamic hip flexion contractions. For a given level of fatigue, the impact on walking function was more profound in individuals with stroke than neurologically intact individuals, and a decreased ability to up regulate hip flexor muscle activity may contribute. These data highlight the importance of monitoring the effect of hip flexor muscle activity during exercise or performance of activities of daily living on walking function post stroke.
\end{abstract}

Keywords: hip flexors, neuromuscular fatigue, gait, stroke

\title{
Introduction
}

Many stroke survivors have leg weakness that limits walking capability[1]. Several studies show an association between baseline weakness of the paretic leg muscles, such as the hip flexors, with abnormalities in the kinematics and kinetics of walking [2-4]. However, less is known about how changes in paretic neuromuscular fatigability (the acute, exercise induced reductions in force [5]) impacts gait function. Accordingly, individuals with stroke demonstrate altered kinematics after short bouts of walking [6-8] and decreased distance walked over 6-minutes compared with healthy controls [9]. Furthermore, people post-stroke exhibit greater fatigability and lesser time to task failure (task duration) of leg muscle than healthy controls [10]. Thus, because individuals with stroke are weaker at baseline and this weakness limits walking function $[3,11]$, stroke-related changes in fatigability could further impair walking deficits.

Gait \& Posture, Vol. 39, No. 4 (April 2014): pg. 1103-1108. DOI. This article is (C Elsevier and permission has been granted for this version to appear in e-Publications@Marquette. Elsevier does not grant permission for this article to be further copied/distributed or hosted elsewhere without the express permission from Elsevier. 
Neuromuscular fatigability post stroke and the effect on walking function is not well characterized [12-14]. Few studies have examined paretic fatigability during repetitive volitional activation of the musculature at sub-maximal force which is functionally relevant to many daily tasks. Recently, we showed that individuals with stroke had decreased task duration for a sustained, sub-maximal contraction of the paretic hip flexors compared with the non-paretic leg when target torques were matched [10]. Declines in torque were negatively associated with self-selected walking speed. Although this work established a potential relationship between hip flexor fatigability and walking function post stroke, there are no studies to date that quantify the effect of paretic hip flexor fatigue on the spatiotemporal and kinematics of over ground walking. This information would be clinically useful in order to optimize strength protocols to offset fatigue-related effects on walking.

Fatigue of the paretic hip flexors, in particular, is likely to significantly impact walking function given their biomechanical importance during walking $[2,11,15-17]$. In healthy individuals, propulsive forces at the ankle are primarily responsible for limb advancement. In contrast, after stroke, the ankle musculature frequently remains paralyzed, decreasing ankle propulsion. In nonfatiguing walking conditions, the hip musculature compensates for force deficits at the ankle [17] and hip power is a predictor of maximal walking speed [3] an index of walking impairment[3, 11]. Use of a hip flexion assist orthosis results in increased walking speed and distance in chronic stroke [18]. Increased dependence on the hip musculature is demonstrated in other disorders with distal weakness [19]. Given the task specificity of neuromuscular fatigability [5] and the increased fatigability of paretic musculature(REF), dynamic fatiguing contractions of the paretic hip flexors may impair power related aspects of walking.

The primary objective of this study was to quantify the effects of hip flexor fatigue on spatiotemporal and kinematics of over ground walking post stroke. We hypothesized that paretic hip flexor fatigue would result in larger decreases in (1) maximal walking speed and distance walked, and (2) joint velocities and range of motion compared with healthy controls. We also quantified muscle activation of several lower limb muscles with electromyogram (EMG) to provide insight into possible mechanisms.

Gait \& Posture, Vol. 39, No. 4 (April 2014): pg. 1103-1108. DOI. This article is @ Elsevier and permission has been granted for this version to appear in e-Publications@Marquette. Elsevier does not grant permission for this article to be further copied/distributed or hosted elsewhere without the express permission from Elsevier. 


\section{Methods}

\section{Subjects}

All activities in this study were approved by Marquette University's Institutional Review Board. All participants gave informed consent before participating in study activities. Ten neurologically intact subjects ( 5 men and 5 women; $62.4 \pm 7.9$ years) and 10 agematched participants with chronic ( $>6$ months) stroke (Table 1 ) participated in this study. Stroke subject inclusion criteria included: single, unilateral stroke (based on information obtained through verbal communication from the physician and consistent with neurological physical examination results), able to ambulate (with or without the use of an assistive device) at least 30ft, and $>6$ months post stroke. Stroke subject exclusion criteria included: history of multiple strokes, brainstem stroke, any uncontrolled medical condition, contractures of any lower extremity joints, and the inability to follow 2-3 step commands.

\begin{tabular}{|c|c|c|c|c|c|c|}
\hline Subject & Ane yeur & Sex & $\begin{array}{l}\text { Memisphere } \\
\text { affiscled }\end{array}$ & $\begin{array}{l}\text { Time since } \\
\text { stroke, manthas }\end{array}$ & $\begin{array}{l}\text { Fupl Meyer (lower } \\
\text { extremify) mux }=34\end{array}$ & $\begin{array}{l}\text { Self-selected } \\
\text { wallinge speed, m/s }\end{array}$ \\
\hline S1 & 64 & $M$ & Left & 66 & zy & 0.78 \\
\hline$\& 2$ & 54 & $M$ & Floght & 55 & 24 & 0.8 \\
\hline 53 & 48 & $M$ & kizhth & 49 & 28 & $a .78$ \\
\hline $54^{43}$ & 65 & $F$ & ten & 79 & 25 & 0.22 \\
\hline $\mathrm{SS}^{2+}$ & 60 & $F$ & Fight & 82 & 23 & a.29 \\
\hline 56 & 64 & F & Kifft & 109 & 32 & 1.04 \\
\hline $57^{\circ}$ & 62 & $M$ & Benth & 90 & 21 & 0.42 \\
\hline ss: & 79 & $F$ & kightit & 95 & 21 & a.14 \\
\hline 59 & 59 & $\mathrm{M}$ & left & 119 & 29 & as \\
\hline$\$ 10$ & 61 & $f$ & Left & 260 & 32 & 068 \\
\hline Meant & 01.6 & & & 100.4 & 262 & abt \\
\hline SD & a. & & & 60.3 & 41 & a.st \\
\hline
\end{tabular}

\section{Force and Power Measurements}

Participants sat at the edge of a height-adjusted plinth with their test leg's hip and knee angles in $30^{\circ}$ flexion (Fig.1). The target range of motion to $80^{\circ}$ of hip flexion was indicated by a laser pointer. A thigh strap was positioned above the knee at $20 \%$ femur length relative to the lateral epicondyle and greater trochanter (Fig.1). A cable $(9.5 \mathrm{~mm}$ diameter) ran between this strap and a custom-built weight stack, which enabled the testing of both dynamic and isometric contractions. Cable tension force was measured with a load cell (Transducer

Gait \& Posture, Vol. 39, No. 4 (April 2014): pg. 1103-1108. DOI. This article is ( Elsevier and permission has been granted for this version to appear in e-Publications@Marquette. Elsevier does not grant permission for this article to be further copied/distributed or hosted elsewhere without the express permission from Elsevier. 
Techniques - SBO series). Cable displacement was measured with a potentiometer (Vishay Electronics-830 $5 \mathrm{k} \Omega$ ) connected to one of the cable pulleys on the weight stack. Force and cable displacement signals were sampled at $1 \mathrm{kHz}$ in Vicon Nexus.

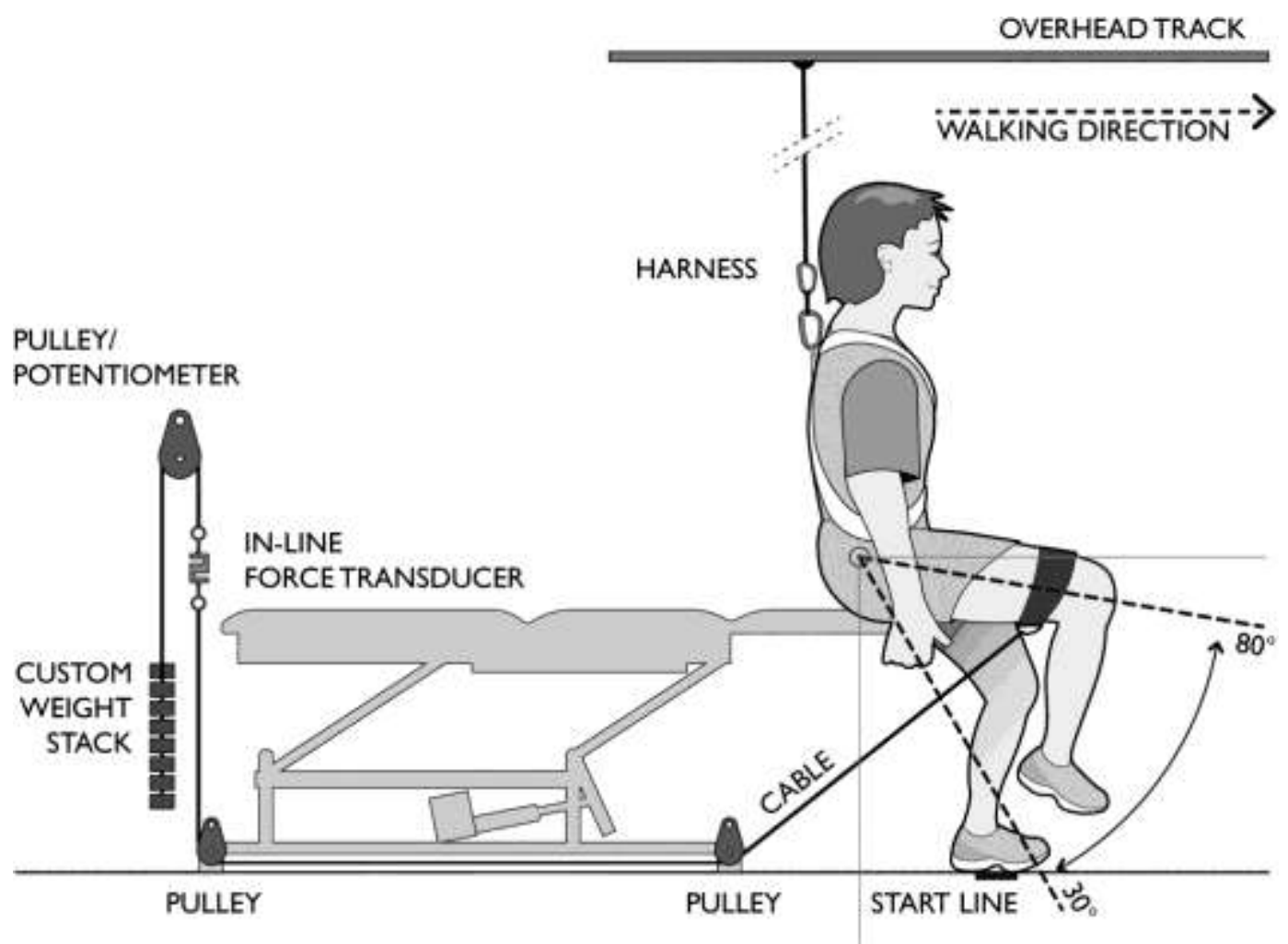

Figure 1. Schematic of the experimental set-up

\section{Motion Analysis Walking Measurements}

To record kinematic data, 15 passive infrared reflective markers were placed at anatomical locations according to the lower extremity Plug-In-Gait model [20]. A six camera Vicon Motion Capture system (100 samples/s), was utilized around an $8.2 \mathrm{~m}$ track, including turning radii. To ensure participants were making similar turning trajectories, a path was indicated on the floor and subjects were given a few practice trials. The data was initially processed in Vicon Nexus to manually label markers, visually indicate gait events, and run the lower extremity Plug-In-Gait model. The walkway contained two AMTI forceplates placed one in front of the other, in the center of the walkway. Gait events were visually detected based upon the locations 
of the heel and toe markers. Toe off was defined as the instant the foot is no longer in contact with the floor, while heel strike was defined as the instant the foot contacts the floor. Ground reaction forces were used to assist in determining event location, when available during the step.

\section{EMG Measurements}

Surface EMG was obtained on the test leg from the vastus medialis (VM), rectus femoris (RF), vastus lateralis (VL), medial hamstring $(\mathrm{MH})$, tibialis anterior (TA), medial gastrocnemius (MG) and soleus. EMG signals were amplified at $1000 \mathrm{~V} / \mathrm{V}$, and bandpass filtered from $20-500 \mathrm{~Hz}$ (Trigno, Delysis Inc., Boston, MA) prior to collection at $1000 \mathrm{~Hz}$ in Vicon Nexus.

\section{Experimental Protocol}

Each participant performed 3-5 baseline isometric hip flexion MVCs and the peak force from the best trial was used (Fig.2). They then completed 3 dynamic contractions (from $30^{\circ}-80^{\circ}$ hip flexion) with a load equivalent to $30 \%$ MVC and was chosen because maximal velocity contractions with a $30 \%$ MVC load corresponds to the maximal power capacity on the power-force curve [21].

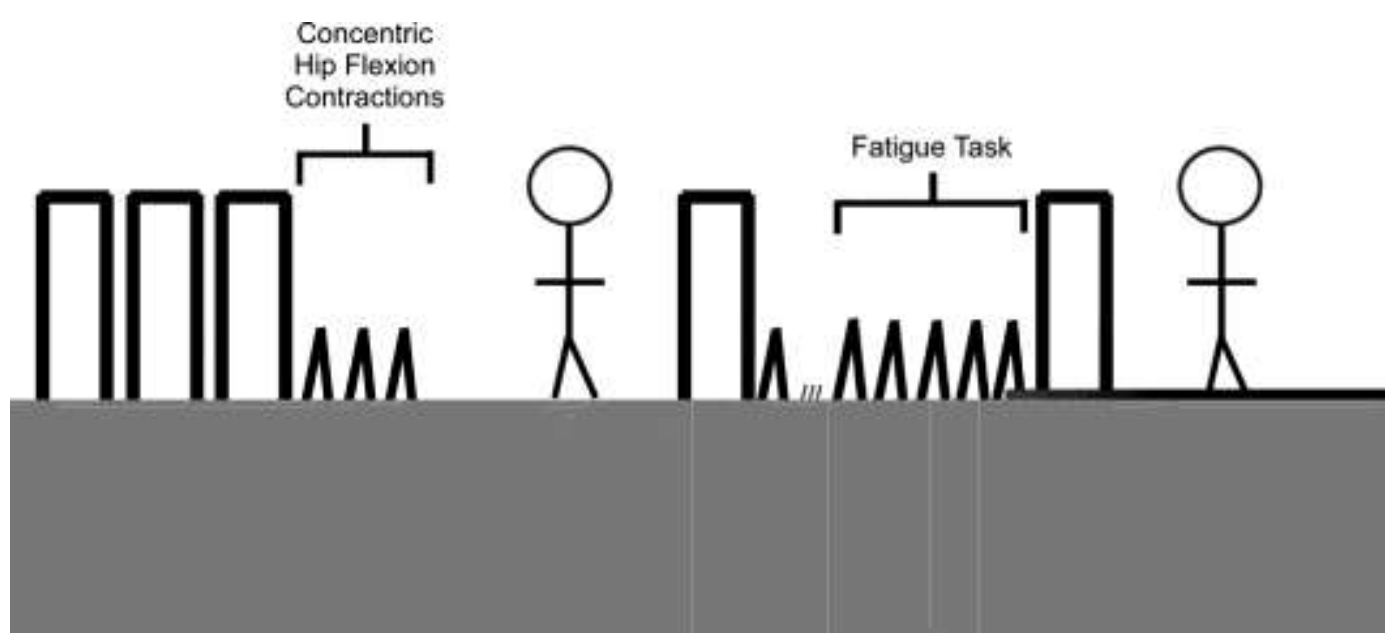

Figure 2. Schematic of the experimental protocol

Over ground walking function was assessed during a six-minute bout of walking. During the straight away of the first lap of each six- 
minute bout, participants were instructed to walk "as fast as they could." At the first turn, they transitioned to a comfortable walking speed for the duration of the time, and were instructed to "cover as much distance as possible." Each participant wore shoes, used an assistive device if needed for safety (see description of participants above), and were secured by a fall arrest harness and track system (Fig.1). Within 10s after termination of the six-minute walk, each participant performed a hip flexion MVC and dynamic power task (with a 30\% MVC load). This combination was repeated three times to determine baseline walking measures with at least 15 minute rest between bouts.

After at least 15 minutes of rest, participants were positioned on the plinth and performed an isometric MVC to confirm that they had returned to baseline values. Next, participants performed repeated intermittent hip flexion contractions (30\% MVC load) until task failure (Fig.2). Task duration was defined as the point in time when the participant failed to flex their hip to the $80^{\circ}$ laser mark three consecutive times. Within $5 \mathrm{~s}$ of task failure each participant performed an MVC, and then began a final six-minute walking bout.

\section{Data Processing and Statistical Analysis}

Data processing was completed in Matlab (Mathworks, Natick, MA). Cable force and position signals were zero phase lowpass filtered at $25 \mathrm{~Hz}$ using a $4^{\text {th }}$-order butterworth filter prior to analysis. MVC amplitude was recorded as the average force during a $100 \mathrm{~ms}$ window surrounding the peak force. Percent decline in MVC was calculated by dividing post-fatigue MVC force by peak pre-fatigue MVC force. Cable movement velocity was calculated from the potentiometer data, and then used with load cell data to calculate peak hip flexion power during each repetition. Peak power for the three hip flexion repetitions was averaged for baseline pre-fatigue trials, and the last four repetitions of the fatigue task.

Kinematic signals were initially low pass filtered at $15 \mathrm{~Hz}$ using a $4^{\text {th }}$ order, zero-phase Butterworth filter. Peak angular velocity and angular range of motion across the gait cycle were calculated for the first lap, which was completed at the individual's maximum walking speed. The following kinematic measures during swing phase were 
compared before and after the fatigue protocol: maximum velocity of hip and knee, range of motion of hip, knee and ankle and hip and knee angle at toe off.

EMG signals were first zero-phase bandpass filtered from 10$250 \mathrm{~Hz}$ using a $4^{\text {th }}$ order Butterworth filter. The root mean square (RMS) of the signals was calculated using a sliding $100 \mathrm{~ms}$ window. RMS area was calculated for all points within a gait cycle greater than $10 \%$ of that cycle's maximum RMS value. Because of the design of the testing apparatus, we could only perform MVC force measurements of the hip flexors. Thus, the pre and post fatigue measurements of the area of the RMS of RF were normalized by the maximum RMS during the hip flexion MVC. For the other muscle groups, a pre:post ratio was calculated (pre area of the RMS/post area of the RMS) for each respective muscle.

Data are reported as means \pm stdev. The Shapiro-Wilk test was used to detect the normality of all variables ( $p<0.05$ indicating a significant deviation from normality) as well as visual inspection of $Q-Q$ plots of each variable. Separate student's t-tests were used to detect significant differences between the paretic and control legs for the following variables: task duration, percent decline in maximal walking speed, baseline MVC force, percent decline in MVC force, percent decline in hip flexion power, the change in the area of the normalized RMS of the EMG for RF and the pre:post ratio for $V L, V M, M H, T A$, Soleus and MG. Separate mixed model ANOVAs were used to detect differences between the paretic and control legs and within groups for time (pre and post fatigue measurements) and interaction effects for the following dependent variables: peak hip flexion power, distance walked, and each of the respective kinematic variables. A Tukey posthoc analysis was used for pairwise comparisons. For both control and stroke groups, Pearson correlation coefficients were calculated to determine relationships between maximal walking speed post fatigue and the following variables: pre fatigue MVC, pre fatigue hip flexion power, pre fatigue MVC and post fatigue MVC. Statistical analyses were performed in SPSS 20.0(IMB, Armonk, NY), with significance accepted at $P<0.05$.

Gait \& Posture, Vol. 39, No. 4 (April 2014): pg. 1103-1108. DOI. This article is ( Elsevier and permission has been granted for this version to appear in e-Publications@Marquette. Elsevier does not grant permission for this article to be further copied/distributed or hosted elsewhere without the express permission from Elsevier. 
NOT THE PUBLISHED VERSION; this is the author's final, peer-reviewed manuscript. The published version may be accessed by following the link in the citation at the bottom of the page.

\section{Results}

\section{Baseline and Fatigue Measurements}

Control subjects had a larger baseline hip flexor MVC force (368 $\pm 137 \mathrm{~N})$ compared with individuals with stroke $(221 \pm 68 \mathrm{~N}, \mathrm{P}<0.05)$. There was no difference in task duration of the fatigue protocol $(P>$ $0.05)$ between controls (68.8 $\pm 46.1 \mathrm{~s})$ and individuals with stroke

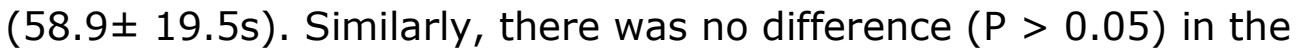
reduction in MVC force or hip flexion power between controls (MVC $=76.3 \pm 17.6 \%$ and power $=61 \pm 16 \%$ of baseline) and individuals with stroke (MVC $=79.5 \pm 14.2 \%$ and power $=51 \pm 12 \%$ of baseline).

\section{Hip Flexion Fatigue and Spatio-temporal Properties of Walking}

Individuals with stroke had significant decline in maximum walking speed post fatigue ( $p r e=0.97 \pm 0.5 \mathrm{~m} / \mathrm{s}$; post $=0.71 \pm .4 \mathrm{~m} / \mathrm{s}, \mathrm{p}$ $<0.05$ ) and the controls subjects did not ( $\mathrm{pre}=1.85 \pm 0.2 \mathrm{~m} / \mathrm{s}$; post $1.80 \pm 0.2 \mathrm{~m} / \mathrm{s}$ ). Individuals with stroke had larger percent declines in maximal walking speed post fatigue compared with controls (Fig. 3, P $<0.05)$. Over the 6 minutes, the controls walked further than the individuals with stroke (426 $\pm 27 \mathrm{~m}$ vs. $231.2 \pm 27 \mathrm{~m}$, respectively, group effect, $\mathrm{P}<0.001)$. There was no significant within-subject effects for time (pre vs. post fatigue, $P>0.05$ ) or interaction effects (group $\times$ time, $\mathrm{P}>0.05)$.

Gait \& Posture, Vol. 39, No. 4 (April 2014): pg. 1103-1108. DOI. This article is (C) Elsevier and permission has been granted for this version to appear in e-Publications@Marquette. Elsevier does not grant permission for this article to be further copied/distributed or hosted elsewhere without the express permission from Elsevier. 


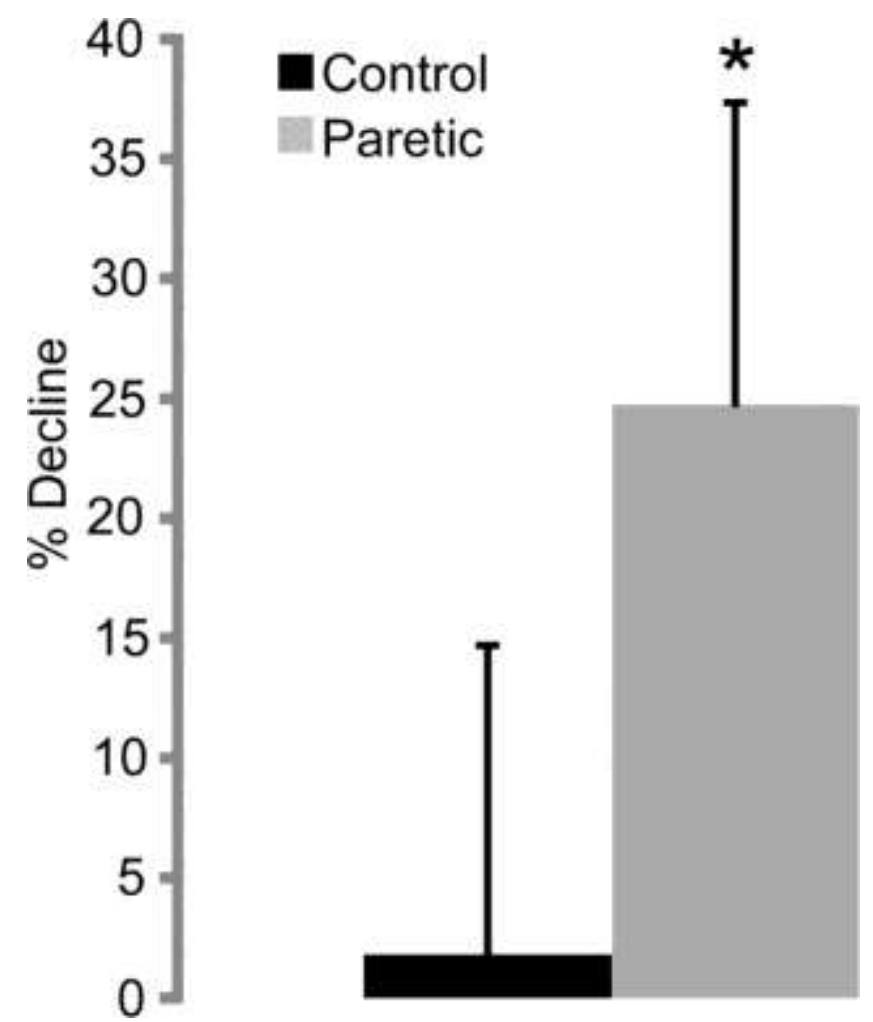

Figure 3. Mean ( \pm SD) percent decline in maximum walking speed post fatiguing hip flexion contractions for the control and paretic legs

\section{EMG}

During the first lap of walking, controls had an increase in the normalized area of RF EMG (Pre $=0.18 \pm 0.11 ;$ Post $=0.33 \pm 0.17 ; \mathrm{P}<$ $0.05)$, but not in any other muscles studied $(P>0.05)$. Stroke participants showed no fatigue-related changes in the normalized area of RF EMG (Pre= $0.44 \pm 0.3$; Post $=0.48 \pm 0.3, P>0.05$ ). Pre: post ratios of EMG area during the first lap of walking were not significantly different between stroke and control groups for any muscles tested ( $P$ $>0.05$ ). Control averages were as follows: $M G=0.95 \pm 0.16$; $\mathrm{MH}=0.63 \pm .15 ; \mathrm{SOL}=1.16 \pm 0.28 ; \mathrm{T}=0.96 \pm 0.22 ; \mathrm{VL}=0.82 \pm 0.37 ;$ $\mathrm{VM}=0.99 \pm 0.46$. Paretic muscle averages were: $\mathrm{MG}=0.95 \pm 0.14$; $\mathrm{MH}=0.78 \pm .22 ; \mathrm{SO}=0.94 \pm 0.14 ; \mathrm{TA}=1.14 \pm 0.47 ; \mathrm{VL}=0.94 \pm 0.14 ;$ $\mathrm{VM}=0.94 \pm 0.15$. 


\section{Effect of Fatigue on Joint Kinematics}

Hip flexion velocity $(\% / s)$ and hip range of motion decreased after the fatiguing contraction (pre-fatigue $>$ post fatigue measurement, time effect, $\mathrm{P}<0.05)$ and controls were faster than the paretic leg (leg effect, $\mathrm{P}<0.001$ ) with a greater range of motion (group effect, $\mathrm{P}=0.009$ ) (Fig.4). There was also an interaction of time and leg for both velocity and range of motion $(P<0.05)$ whereby the paretic leg had larger decreases in maximal hip flexion velocity and less range of motion following the fatiguing contraction than controls (Fig.4).
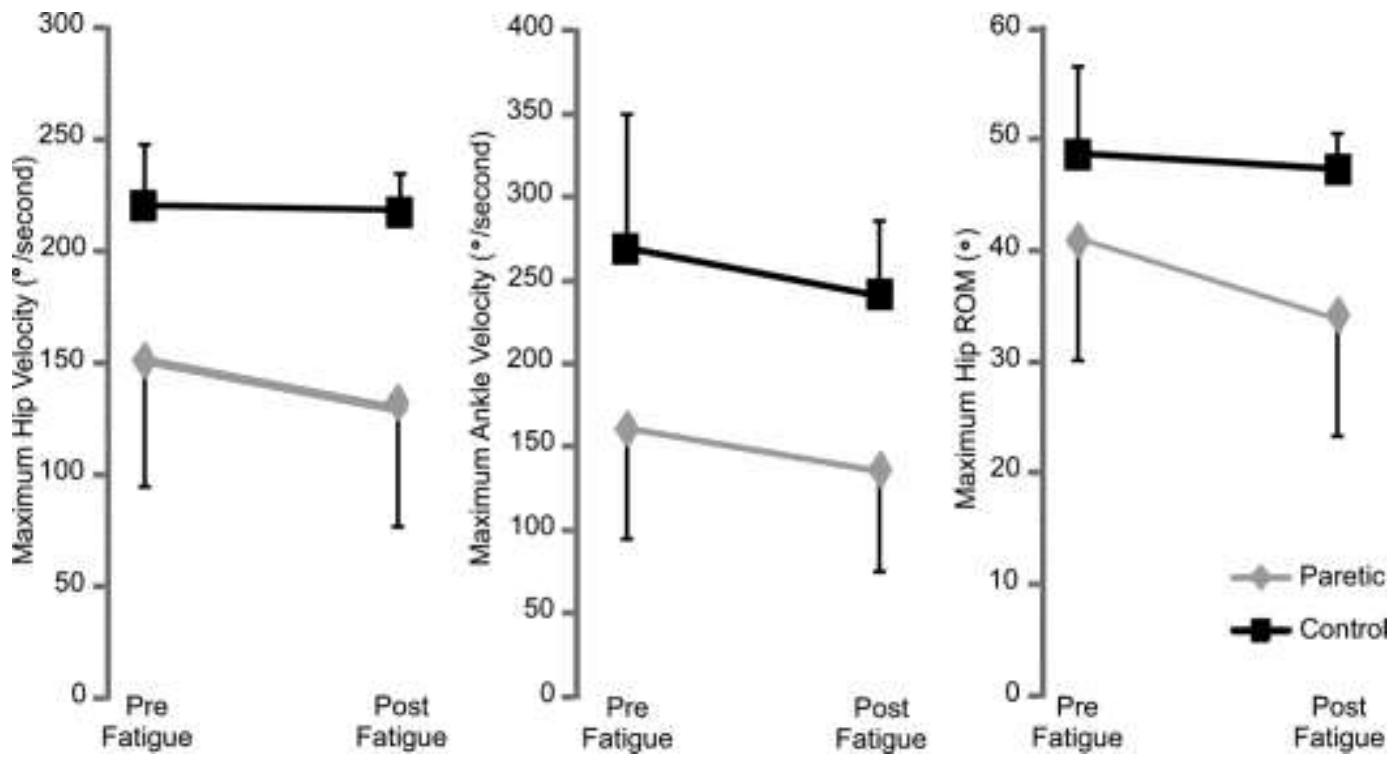

Figure 4. Changes in joint kinematics between stroke and control subjects during first walking lap pre and post fatiguing contractions

Similar to hip flexion velocity, maximal ankle velocity was greater for controls compared with stroke $(P<0.05)$ and decreased after the fatiguing contractions in both groups $(P<0.05)$. However there was no interaction (group $\times$ time, $\mathrm{P}>0.05$, Fig.4).

There were no fatigue-related differences in the following variables for the stroke or controls groups: knee maximum velocity, knee range of motion, knee angle at toe off, total ankle range of motion, and hip angle at toe off for stroke or controls $(P>0.05)$. 


\section{Correlations with Maximal Walking Speed and Strength}

In stroke participants, maximal walking speed after the fatiguing contraction was positively correlated with pre-fatigue hip flexion power $\left(r^{2}=0.85\right)$, post fatigue hip flexion power $\left(r^{2}=0.7\right)$, and paretic hip velocity pre fatigue $\left(r^{2}=0.65\right)$ and post fatigue $\left(r^{2}=0.67\right)$. Post fatigue maximal walking speed was not significantly correlated with prefatigue or post-fatigue hip flexion MVCs.

\section{Discussion}

\section{Summary of Results}

We found that fatigability induced in the hip flexor muscles of people with and without stroke, had larger functional consequences for people with stroke including slower walking and larger alterations in lower limb kinematics. Compared with controls following fatiguing dynamic hip flexion contractions, stroke participants showed 1) larger relative reductions in maximal walking speed, 2) greater decrements in hip range of motion and peak velocity during swing, and 3) lack of modulation of hip flexor muscle activation (EMG). Both groups were fatigued to similar physiological levels because there was no difference in task duration for the fatiguing contraction of the hip flexors and the reduction in MVC following the fatiguing contraction. This result is consistent with data from a previous study in which individuals with stroke had similar task duration as the non-paretic and control legs when effort levels (i.e. same relative intensity of MVC) were matched [10]. Our interpretation was that because the paretic leg has lower baseline MVC forces, the absolute target torques during the equal effort fatiguing contractions were lower thus allowing the participants to sustain the contraction longer. Thus, for the present study, for a similar level of fatigability, the impact on walking function was more profound (maximal walking speed and joint kinematics) in individuals with stroke compared with controls. For participants with stroke, this was accompanied by a lack of increase in EMG activity of the rectus femoris during the walking after the fatiguing contraction, where in healthy controls there was an increase in EMG. Overall, the lack of ability to compensate for losses in hip range of motion and velocity and minimal increases in RF activation post fatigue suggest a

Gait \& Posture, Vol. 39, No. 4 (April 2014): pg. 1103-1108. DOI. This article is (C) Elsevier and permission has been granted for this version to appear in e-Publications@Marquette. Elsevier does not grant permission for this article to be further copied/distributed or hosted elsewhere without the express permission from Elsevier. 
deficiency in the nervous system to compensate for single muscle fatigability during walking.

\section{Possible Mechanisms of Stroke-related Impact of Fatigue on Maximal Walking Speed}

Controls demonstrated increased RF muscle activity (a hip flexor) during walking post fatigue but those with stroke did not. Individuals with stroke may have limited ability to modulate agonist muscle activity needed to generate a given force. It is plausible that there was a concurrent lack of modulation of other paretic hip flexors such as Ilioposas group. Other studies show saturation in paretic motor unit firing rates and altered recruitment strategies with increasing load levels [22-24]. Our data support these findings because the global RF EMG activity was already elevated at the start of walking relative to controls, and then failed to increase. Both of these deficits would hamper continued force generation and the ability to increase force as the muscle fatigued. Controls are able to up regulate muscle behavior in response to submaximal fatiguing exercise, by recruiting more motor units to compensate as the already active motor units in the agonist muscles become progressively fatigued [25].

In addition to a decreased ability to modulate muscle activity, individuals with stroke showed less ability to compensate for hip flexor muscle fatigue with other muscle groups compared with people without stroke. We did not see evidence of any other muscle groups increasing their activity or modulation in range of motion by other joints to compensate for range of motion or velocity losses in the paretic hip. Instead, individuals with stroke had declines in hip flexion velocity and range of motion and ankle velocity. This highlights the importance of the paretic hip flexors in gait post stroke and limitations in compensatory strategies in the paretic leg in response to a fatiguing task.

\section{Study Limitations}

There were several limitations to this study. We purposely fatigued one muscle group in this study but simultaneous fatigue of more than one muscle group may have a greater impact on distance

Gait \& Posture, Vol. 39, No. 4 (April 2014): pg. 1103-1108. DOI. This article is (C) Elsevier and permission has been granted for this version to appear in e-Publications@Marquette. Elsevier does not grant permission for this article to be further copied/distributed or hosted elsewhere without the express permission from Elsevier. 
walked in people with stroke. In addition, technical challenges limited us to record activation of one hip flexor (rectus femoris), and not the iliopsoas. Measurement of iliopsoas activation, may provide additional insight into the synergistic activity of the hip flexors work during a fatiguing contraction and compensatory responses in individuals with and without stroke. Finally, although our group of individuals with stroke was heterogenous in baseline walking function and motor impairment. Future studies will identify the relation between impairment level and hip flexion fatigability on walking function in community and noncommunity ambulators.

\section{Highlights Research}

- Ten individuals with chronic stroke and 10 without stroke (controls) participated

- Both groups had similar task durations and reductions in MVC force post-fatigue

- Individuals with stroke had larger percent reductions in walking speed

- Individuals with stroke had greater decrements in hip and ankle kinematics

- At a given level of fatigue, impact on walking function was more profound in stroke

\section{Acknowledgements}

This study was supported by the American Heart Association: Clinical Research Program (10CRP2580011) and Clinical \& Translational Science Institute (KL2RR031972). The authors are very grateful to Dr. Brian D. Schmit for consultation on data analysis and use of equipment.

Publisher's Disclaimer: This is a PDF file of an unedited manuscript that has been accepted for publication. As a service to our customers we are providing this early version of the manuscript. The manuscript will undergo copyediting, typesetting, and review of the resulting proof before it is published in its final citable form. Please note that during the production process errors may be discovered which could affect the content, and all legal disclaimers that apply to the journal pertain.

Gait \& Posture, Vol. 39, No. 4 (April 2014): pg. 1103-1108. DOI. This article is ( Elsevier and permission has been granted for this version to appear in e-Publications@Marquette. Elsevier does not grant permission for this article to be further copied/distributed or hosted elsewhere without the express permission from Elsevier. 
NOT THE PUBLISHED VERSION; this is the author's final, peer-reviewed manuscript. The published version may be accessed by following the link in the citation at the bottom of the page.

\section{References}

1. Lloyd-Jones D, et al. Heart disease and stroke statistics--2009 update: a report from the American Heart Association Statistics Committee and Stroke Statistics Subcommittee. Circulation. 2009;119(3):e21-e181.

2. Nadeau $S$, et al. Analysis of the clinical factors determining natural and maximal gait speeds in adults with a stroke. Am J Phys Med Rehabil. $1999 ; 78(2): 123-130$.

3. Jonkers I, Delp S, Patten C. Capacity to increase walking speed is limited by impaired hip and ankle power generation in lower functioning persons post-stroke. Gait Posture. 2009;29(1):129-137.

4. Chen G, Patten $C$. Joint moment work during the stance-to-swing transition in hemiparetic subjects. J Biomech. 2008;41(4):877-883.

5. Enoka RM, Duchateau J. Muscle fatigue: what, why and how it influences muscle function. J Physiol. 2008;586(1):11-23.

6. Dean CM, Richards CL, Malouin F. Walking speed over 10 metres overestimates locomotor capacity after stroke. Clin Rehabil. $2001 ; 15(4): 415-421$.

7. Bayat R, Barbeau H, Lamontagne A. Speed and temporal-distance adaptations during treadmill and overground walking following stroke. Neurorehabil Neural Repair. 2005;19(2):115-124.

8. Sibley KM, et al. Effects of extended effortful activity on spatio-temporal parameters of gait in individuals with stroke. Gait Posture. $2008 ; 27(3): 387-392$.

9. Pohl PS, et al. Influence of stroke-related impairments on performance in 6-minute walk test. J Rehabil Res Dev. 2002;39(4):439-444.

10. Hyngstrom AS, et al. Stroke-related changes in neuromuscular fatigue of the hip flexors and functional implications. Am J Phys Med Rehabil. 2012;91(1):33-42.

11. Milot MH, Nadeau S, Gravel D. Muscular utilization of the plantarflexors, hip flexors and extensors in persons with hemiparesis walking at selfselected and maximal speeds. J Electromyogr Kinesiol. 2007;17(2):184-193.

12. Gerrits $\mathrm{KH}$, et al. Isometric muscle function of knee extensors and the relation with functional performance in patients with stroke. Arch Phys Med Rehabil. 2009;90(3):480-487.

13. Riley NA, Bilodeau M. Changes in upper limb joint torque patterns and EMG signals with fatigue following a stroke. Disabil Rehabil. 2002;24(18):961-969.

14. Knorr S, et al. The origins of neuromuscular fatigue post-stroke. Exp Brain Res. 2011;214(2):303-315.

15. Perry J. Gait Analysis. Thorofare: SLACK; 1992.

Gait \& Posture, Vol. 39, No. 4 (April 2014): pg. 1103-1108. DOI. This article is (C) Elsevier and permission has been granted for this version to appear in e-Publications@Marquette. Elsevier does not grant permission for this article to be further copied/distributed or hosted elsewhere without the express permission from Elsevier. 
16. Kim CM, Eng JJ. The relationship of lower-extremity muscle torque to locomotor performance in people with stroke. Phys Ther. 2003;83(1):49-57.

17. Nadeau $S$, et al. Plantarflexor weakness as a limiting factor of gait speed in stroke subjects and the compensating role of hip flexors. Clin Biomech (Bristol, Avon) 1999;14(2):125-135.

18. Carda $S$, et al. Efficacy of a hip flexion assist orthosis in adults with hemiparesis after stroke. Phys Ther. 2012;92(5):734-739.

19. Ramdharry GM, et al. Hip flexor fatigue limits walking in Charcot-MarieTooth disease. Muscle Nerve. 2009;40(1):103-111.

20. RB D, et al. A gait analysis data collection and reduction technique. Human Movement Science. 1991;10:575-587.

21. Caiozzo V. In: ACSM's Advanced Exercise Physiology. 2nd ed. Farrell P JM, Caiozzo V, editors. Baltimore, MD: MD: American College of Sports Medicine; 2012. pp. 117-151.

22. Chou LW, et al. Motor unit rate coding is severely impaired during forceful and fast muscular contractions in individuals post stroke. J Neurophysiol. 2013;109(12):2947-2954.

23. Chang SH, et al. Spasticity, weakness, force variability, and sustained spontaneous motor unit discharges of resting spastic-paretic biceps brachii muscles in chronic stroke. Muscle Nerve. 2013;48(1):85-92.

24. Mottram CJ, et al. Origins of abnormal excitability in biceps brachii motoneurons of spastic-paretic stroke survivors. J Neurophysiol. 2009;102(4):2026-2038.

25. Riley ZA, et al. Motor unit recruitment in human biceps brachii during sustained voluntary contractions. J Physiol. 2008;586(8):2183-2193.

Gait \& Posture, Vol. 39, No. 4 (April 2014): pg. 1103-1108. DOI. This article is (C Elsevier and permission has been granted for this version to appear in e-Publications@Marquette. Elsevier does not grant permission for this article to be further copied/distributed or hosted elsewhere without the express permission from Elsevier. 